\title{
Effect of inductor parasitic resistances on the voltage gain of high step-up DC-DC converters for electric vehicle applications
}

ISSN 1755-4535

Received on 15th May 2017 Revised 10th December 2017 Accepted on 16th January 2018 doi: 10.1049/iet-pel.2017.0361 www.ietdl.org

\author{
Wilmar Martinez ${ }^{1,2} \bowtie$, Camilo Cortes², Masayoshi Yamamoto ${ }^{3}$, Jun Imaoka ${ }^{3}$ \\ ${ }^{1} \mathrm{KU}$ Leuven, Diepenbeek Campus, Diepenbeek, Belgium \\ ${ }^{2}$ Universidad Nacional de Colombia, Bogota, Colombia \\ ${ }^{3}$ Nagoya University, Nagoya, Japan \\ 凶E-mail: wilmar.martinez@kuleuven.be
}

\begin{abstract}
Reconfiguration, sizing and downsizing of the storage unit, in electrically propelled vehicles, are techniques that have been reported effective to improve the shelf life and performance of the storage cells. However, these solutions might decrease the rated voltage of the storage unit and therefore DC-DC converters with high voltage gain are suitable solutions to connect these low-voltage units to the motor drive, keeping a good performance of the vehicle. Moreover, parasitic resistances presented in the components of these converters have proved to influence the efficiency and the voltage gain of the converter. The ideal voltage gain of four high step-up converters is analysed, derived, and compared. These converters were selected because of their potential to be applied in electric mobility and their similarity in the techniques that use to achieve high voltage gain: interleaving phases and magnetic integration. One of the analysed topologies is proposed by the authors. Afterwards, the parasitic resistance effect is analysed to obtain the non-ideal voltage gain and the efficiency of these four topologies. Finally, the topology that presents the best trade-off between the non-ideal voltage gain and the efficiency is experimentally tested with a $100 \mathrm{~W}$ prototype
\end{abstract}

\section{Introduction}

Electrically propelled vehicles, such as pure electric vehicles, hybrid electric vehicles (HEVs), fuel cell electric vehicles etc. are emerging technologies with a growing interest because they can tackle some of the sustainability issues of transportation systems. This is possible because these vehicles have been improved to reduce energy consumption and greenhouse gas emissions [1-3].

These vehicles demand efficient, compact, and light high-power converters to maximise the use of the stored energy, obtaining enough torque, power, autonomy, and the required speed for the daily needs of the users, especially in places with varying topography and unstable soils [4-7].

At the same time, the energy storage system, e.g. a battery pack in most cases, contributes with a considerable amount of mass, volume, and cost due to the number of storage cells required to offer the needed voltage [8]. Moreover, the worst cell in the pack stack determines the degradation of the total system. As a result, the probability of a failure is increased due to the large number of storage cells [9]. Additionally, the efficiency of the storage system is decreased because of the presence of balancing circuits (either passive or active) that depend on the number of storage cells. These circuits produce power losses, heat, and pack degradation [10]. In consequence, the shelf-life and the rated voltage of the pack is considerably reduced and the costs of the system increase.

In this context, the storage pack reconfiguration, sizing, and downsizing are effective techniques to improve its use, to enable easy recovery from failures, and to reduce the total cost of the storage unit [8-10]. However, a consequence of the storage pack reconfiguration is that the rated voltage is drastically reduced.

As an example, a progressive battery pack reduction and voltage conversion increase have been seen in the Toyota Prius generations. The first generation had a $288 \mathrm{~V}$ battery with a $33 \mathrm{~kW}$ motor and a voltage conversion of 1 (without DC-DC converter). The second generation had a $202 \mathrm{~V}$ battery with a $500 \mathrm{~V} 50 \mathrm{~kW}$ motor, i.e. a voltage conversion of 2.47 . The third and fourth generations of the basic Prius have a $202 \mathrm{~V}$ battery with a $650 \mathrm{~V}$ $60 \mathrm{~kW}$ motor and a voltage conversion of 3.21. Finally, the case of the Prius C (Prius Alfa in some countries) is remarkable because it has a $144 \mathrm{~V}$ battery, a $520 \mathrm{~V} 45 \mathrm{~kW}$ motor and a voltage conversion of $3.61[9,11,12]$. It is evident how the automotive industry is moving towards the storage pack reconfiguration, sizing, and downsizing, as well as the increase of the motor voltage and subsequently of the voltage conversion. In that way, if the battery is reduced up to $100 \mathrm{~V}$, and a $650 \mathrm{~V} 60 \mathrm{~kW}$ motor is used, a voltage gain of 6.5 will be required. In addition, when parasitic components are considered, voltage gains of three or higher become hard to obtain by conventional boost converters.

These operating conditions cause an increment in the losses of the DC-DC power converter that works between the storage unit and the motor inverter [8]. HEVs have been using conventional step-up topologies for some time, including single-phase boost converters and the well-known interleaved boost converter with coupled inductors, that uses magnetic coupling techniques to offer downsizing and ripple reduction [13, 14]. However, these topologies present some problems due to three reasons: (i) a high duty cycle is needed to obtain the required output voltage, but high duty cycles produce extremely high losses in the semiconductors due to the parasitic effects; (ii) voltage stresses in power switches and diodes are equal to the output voltage, which demands higher requirements to the selected components; and finally, (iii) conventional converters have reverse-recovery problems that increase the power losses and require large cooling systems, with the consequence of lower efficiency and power density $[15,16]$. As a result, the demand of high step-up (HSU) conversion and highpower techniques has gradually increased according to the downsizing requirements and low-voltage energy sources in these vehicles [16-19].

On the other hand, when an HSU operation is required in a power converter, the input current tends to be large and the voltage drop at the internal parasitic resistances of each component compromises the converter efficiency and the voltage gain itself. For this reason, in order to have a better understanding of the capabilities of a DC-DC converter, it is important to analyse the effect of the parasitic components in the voltage conversion [2022]. This paper focuses on the study and comparison of four different HSU topologies, shown in Fig. 1, with the potential of being applied in electric mobility. Specifically, the analysis of the 

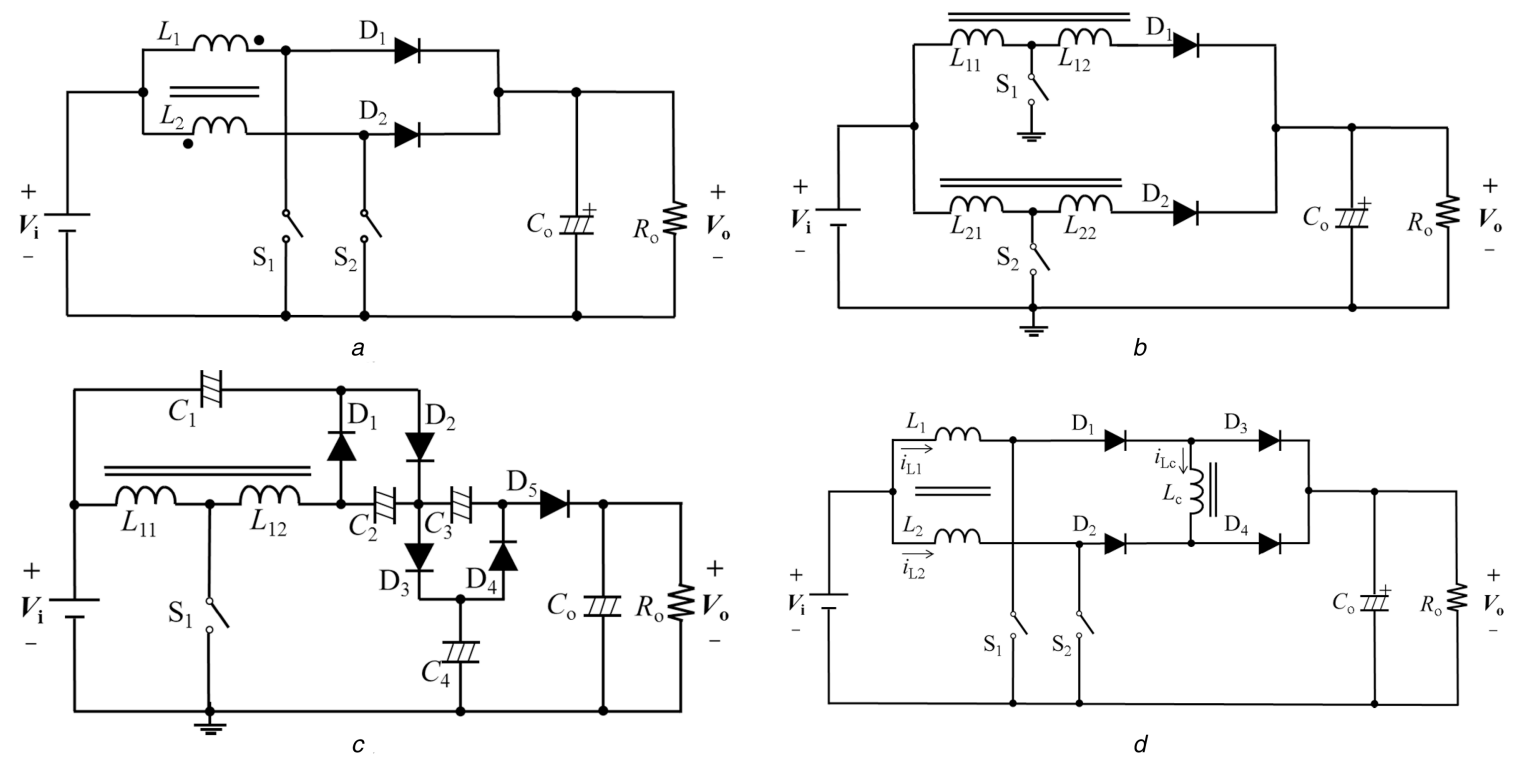

Fig. 1 Analysed converters

(a) Two-phase interleaved boost converter with coupled inductor, (b) Two-phase interleaved tapped-inductor converter, (c) 'Super' tapped-inductor converter, (d) Interleaved boost converter with integrated coupled inductor

ideal and non-ideal voltage gain, and the efficiency of the studied converters are reported in this paper. The non-ideal voltage gain and the efficiency are evaluated having in mind that parasitic resistances in the windings (copper resistance) usually produce the biggest impact on the voltage gain, especially where multiple windings are used [13]. These calculations are conducted using small-ripple approximation, voltage-second balance and capacitorcharge balance. As a result of this analysis, the topology with the best combination of voltage gain (ideal and non-ideal) and efficiency is experimentally tested using a $100 \mathrm{~W}$ prototype.

The selected converters, shown in Fig. 1, are intended to be applied in electric mobility due to their potential for high-power applications. The aforesaid notwithstanding, as they are HSU converters, the analysis, derivation, and comparison presented in this paper are equally applicable to photovoltaic (PV) and fuel cell applications where high voltage gains are required, especially in grid connected systems [23-25].

\section{Interleaved boost converter}

Fig. $1 a$ shows the well-known two-phase interleaved boost converter with coupled inductors. This converter has been widely studied for many applications, especially for electric mobility because of its well-known characteristics. This topology has two windings $L_{1}$ and $L_{2}$ that are wound only into one magnetic core. This feature achieves a direct or inverse magnetic coupling depending on the wound direction of the windings. This converter has two switches $S_{1}$ and $S_{2}$ that are commutated with a phase shift of $180^{\circ}$, two main diodes $D_{1}$ and $D_{2}$, and one output capacitor $C_{\mathrm{o}}$ [26-31].

The two-phase interleaved boost converter combines two main techniques: interleaving phases and magnetic coupling. Multiphase interleaved topologies have been widely used, due to three attractive features. First, the total input current is shared among several phases; for this reason, it is possible to drive high currents without using power devices with high current ratings. Second, interleaved techniques can achieve high-frequency operation in the output capacitor without driving the power semiconductor devices at the same high frequency [32-36]. Third, filter components can be miniaturised and EMI emissions can be reduced [37-39]. Considering these features, this topology is effective for highpower density applications.

On the other hand, magnetic coupling has been used in multiphase interleaved converters in order to reduce the volume and mass of magnetic components. The advantages of this method are given by the integration of several windings into only one core. In addition, magnetic integration produces a magnetic coupling that might reduce the DC flux, depending on the coupling type. Consequently, the core size can be reduced as well [39].

Although this topology has several advantages, the interleaved boost converter with coupled-inductor presents the same ideal voltage-gain problem of the conventional single-phase boost converter, i.e. at high duty cycles, power losses are increased and voltage gain is highly decreased. The ideal voltage-gain $M$ of this converter is expressed as

$$
M_{\text {boost }}=\frac{1}{1-D}
$$

where $D$ is defined as the duty cycle.

Considering the parasitic resistance effect in the windings, Fig. 2 shows the interleaved boost converter with the copper resistances of the coupled-inductor $R_{\mathrm{L} 1,2}$, as well as the operating modes resulting of the combination of the $\mathrm{ON}$ and OFF states of the switches.

Assuming that the two phases are structurally symmetric and the windings are composed of wires with the same cross-sectional area, it is possible to state:

$$
\begin{gathered}
R_{\mathrm{L}}=R_{\mathrm{L} 1}=R_{\mathrm{L} 2} \\
i_{\mathrm{L}}=i_{\mathrm{L} 1}=i_{\mathrm{L} 2}
\end{gathered}
$$

where $i_{\mathrm{L} 1,2}$ are the winding currents in each phase. Then, the steady-state analysis is conducted and each operating mode is evaluated as follows:

Mode 1

$$
\begin{aligned}
& v_{\mathrm{L} 1}=V_{\mathrm{i}}-i_{\mathrm{L}} R_{\mathrm{L}} \\
& v_{\mathrm{L} 2}=V_{\mathrm{i}}-i_{\mathrm{L}} R_{\mathrm{L}}-V_{\mathrm{o}} \\
& i_{\mathrm{Co}}=i_{\mathrm{L}}-\frac{V_{\mathrm{o}}}{R_{\mathrm{O}}}
\end{aligned}
$$

Mode 2

$$
\begin{aligned}
& v_{\mathrm{L} 1}=V_{\mathrm{i}}-i_{\mathrm{L}} R_{\mathrm{L}}-V_{\mathrm{o}} \\
& v_{\mathrm{L} 2}=V_{\mathrm{i}}-i_{\mathrm{L}} R_{\mathrm{L}} \\
& i_{\mathrm{Co}}=i_{\mathrm{L}}-\frac{V_{\mathrm{o}}}{R_{\mathrm{O}}}
\end{aligned}
$$




$$
\begin{aligned}
& v_{\mathrm{L} 1}=v_{\mathrm{i}}-i_{\mathrm{L}} R_{\mathrm{L}}-V_{\mathrm{o}} \\
& v_{\mathrm{L} 2}=v_{\mathrm{i}}-i_{\mathrm{L}} R_{\mathrm{L}}-V_{\mathrm{o}} \\
& i_{\mathrm{Co}}=2 i_{\mathrm{L}}-\frac{V_{\mathrm{o}}}{R_{\mathrm{o}}}
\end{aligned}
$$

Mode 4

$$
\begin{aligned}
& v_{\mathrm{L} 1}=v_{\mathrm{i}}-i_{\mathrm{L}} R_{\mathrm{L}} \\
& v_{\mathrm{L} 2}=v_{\mathrm{i}}-i_{\mathrm{L}} R_{\mathrm{L}} \\
& i_{\mathrm{Co}}=-\frac{V_{\mathrm{o}}}{R_{\mathrm{o}}}
\end{aligned}
$$

It is possible to derive the ratio of output and input voltage by the combination of (4)-(7) with their respective duty cycle cases. Thus, the non-ideal voltage gain with the parasitic effect of the copper resistance is derived:

$$
M_{\text {boostnon-ideal }}=\frac{1}{(1-D)\left(1+\left(R_{\mathrm{L}} /\left(R_{\mathrm{o}}(1-D)^{2}\right)\right)\right)}
$$

Fig. $3 a$ shows the plot of (8) considering several values of copper resistance ratios between the windings and the load $\left(R_{\mathrm{L}} / R_{\mathrm{O}}\right)$. The ratio $R_{\mathrm{L}} / R_{\mathrm{O}}$ is used because it is an effective way to measure the effect of the parasitic resistance in general conditions, i.e. specific parameters are not required for the evaluation.

Fig. $3 a$ shows the effect of inductors' copper resistance on the voltage gain. It is evident how the increase of the copper resistance or the reduction of the load (a power increase) compromise the voltage gain to the point of reducing it to zero at high duty cycles, although ideally it is supposed to obtain a quite large voltage gain. For these reasons, HSU converters with low impact of the copper resistance on the voltage gain are required by the industry.

Equally important is the efficiency performance of HSU converters. Then, combining (8) and the duty cycle cases, it is possible to derive the efficiency expression of the converter considering the parasitic resistances, i.e. (9). The efficiency of the boost converter at several ratios $R_{\mathrm{L}} / R_{\mathrm{O}}$ is shown in Fig. $3 b$

$$
\eta_{\text {boost }}=\frac{1}{1+\left(R_{\mathrm{L}} /\left(R_{\mathrm{o}}(1-D)^{2}\right)\right)}=(1-D) M_{\text {boostnon -ideal }}
$$

\section{Interleaved tapped-inductor converter}

Fig. $1 b$ shows the two-phase interleaved tapped-inductor converter, which is an improved converter that combines the advantages of the interleaved multi-phases and the magnetic coupling. This converter has two switches $S_{1}$ and $S_{2}$ that are commutated with a phase shift of $180^{\circ}$, two main diodes $D_{1}$ and $D_{2}$, one output capacitor $C_{0}$, and two special inductors $L_{11}$ with $L_{12}$ and $L_{21}$ with $L_{22}$. Each of these inductors has two windings, $L_{x 1}$ and $L_{x 2}$ installed in the same core, i.e. they are magnetically coupled. Each winding, $L_{x 1}$ and $L_{x 2}$, belongs to the same inductor, but they are separated by a tap, which gives the converter its name. In this converter, $N$ is introduced as the ratio between the number of turns of each winding $N_{x 2}$ and $N_{x 1}\left(N=N_{x 2} / N_{x 1}\right)$ [40-43].

When this converter is under continuous conduction mode (CCM), the relation between the output and input voltage is dependent on $N$, and its ideal voltage gain has been reported in [43] as

$$
M_{\mathrm{tapped}}=\frac{1+N D}{1-D}
$$

When $N$ is increased, the voltage gain of the tapped-inductor converter increases as well. This voltage gain is higher than the one of the conventional boost converter.

The parasitic analysis is conducted considering the same assumptions of the basic interleaved boost converter. Fig. 4 shows the tapped-inductor converter with each inductor's copper resistance: $R_{\mathrm{L} 11,12,21,22}$, as well as each of the four operating modes.
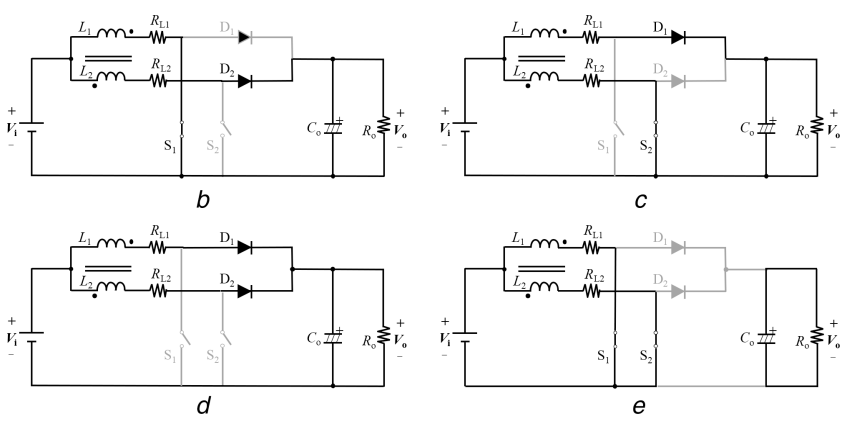

Fig. 2 Two-phase interleaved boost converter with parasitic resistances (a) Schematic, (b) Mode 1, (c) Mode 2, (d) Mode 3, (e) Mode 4
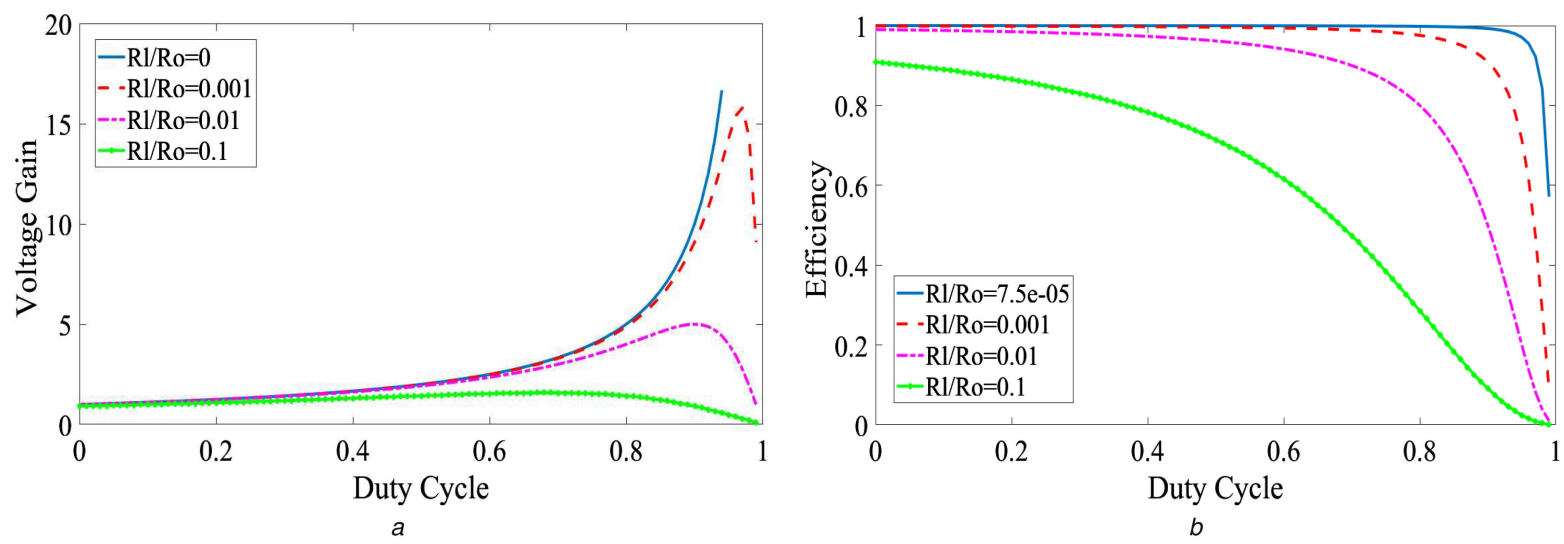

Fig. 3 Non-ideal voltage gain and efficiency of the interleaved boost converter (a) Non-ideal voltage gain of the interleaved boost converter for $R_{\mathrm{L} 1} / R_{\mathrm{O}}=0-0.1$, (b) Efficiency of the interleaved boost converter for $R_{\mathrm{L} 1} / R_{\mathrm{O}}=0.1-0.000075$ 
Considering a symmetrical condition between the phases, the four parasitic resistances can be expressed as

$$
\begin{gathered}
R_{\mathrm{L} 1}=R_{\mathrm{L} 11}=R_{\mathrm{L} 21} \\
R_{\mathrm{L} 2}=R_{\mathrm{L} 21}=R_{\mathrm{L} 22} \\
R_{\mathrm{L} 2}=N R_{\mathrm{L} 1}
\end{gathered}
$$

Based on the steady-state analysis presented in [22, 44], it is possible to obtain the state equations of each operating mode as follows:

Mode 1

$$
\begin{aligned}
& v_{\mathrm{L} 11}=V_{\mathrm{i}}-i_{\mathrm{L} 11} R_{\mathrm{L} 1} \\
& v_{\mathrm{L} 21}=V_{\mathrm{i}}-i_{\mathrm{L} 21} R_{\mathrm{L} 1}-i_{\mathrm{L} 21} R_{\mathrm{L} 2}-V_{\mathrm{o}} \\
& i_{\mathrm{Co}}=i_{\mathrm{L} 21}-\frac{V_{\mathrm{o}}}{R_{\mathrm{o}}}
\end{aligned}
$$

Mode 2

$$
\begin{aligned}
& v_{\mathrm{L} 11}=V_{\mathrm{i}}-i_{\mathrm{L} 11} R_{\mathrm{L} 1}-i_{\mathrm{L} 11} R_{\mathrm{L} 2}-V_{\mathrm{o}} \\
& v_{\mathrm{L} 21}=V_{\mathrm{i}}-i_{\mathrm{L} 21} R_{\mathrm{L} 1} \\
& i_{\mathrm{Co}}=i_{\mathrm{L} 11}-\frac{V_{\mathrm{o}}}{R_{\mathrm{o}}}
\end{aligned}
$$

Mode 3

$$
\begin{aligned}
& v_{\mathrm{L} 11}=V_{\mathrm{i}}-i_{\mathrm{L} 11} R_{\mathrm{L} 1}-i_{\mathrm{L} 11} R_{\mathrm{L} 2}-V_{\mathrm{o}} \\
& v_{\mathrm{L} 21}=V_{\mathrm{i}}-i_{\mathrm{L} 21} R_{\mathrm{L} 1}-i_{\mathrm{L} 21} R_{\mathrm{L} 2}-V_{\mathrm{o}} \\
& i_{\mathrm{Co}}=\left(i_{\mathrm{L} 11}+i_{\mathrm{L} 21}\right)-\frac{V_{\mathrm{o}}}{R_{\mathrm{o}}}
\end{aligned}
$$

Mode 4

$$
\begin{aligned}
& v_{\mathrm{L} 11}=V_{\mathrm{i}}-i_{\mathrm{L} 11} R_{\mathrm{L} 1} \\
& v_{\mathrm{L} 21}=V_{\mathrm{i}}-i_{\mathrm{L} 21} R_{\mathrm{L} 1} \\
& i_{\mathrm{Co}}=-\frac{V_{\mathrm{o}}}{R_{\mathrm{o}}}
\end{aligned}
$$

Equation (18) presents the non-ideal voltage expression from each duty cycle condition derived from (14)-(17)

$$
\begin{aligned}
& M_{\text {tapped non - ideal }} \\
& =\frac{(1+N D)(1-D)}{\left(R_{\mathrm{L} 1} / R_{\mathrm{O}}\right) D(1+N)^{2}+\left(\left(R_{\mathrm{L} 1}+R_{\mathrm{L} 2}\right) / R_{\mathrm{o}}\right)(1-D)+(1-D)^{2}}
\end{aligned}
$$

Fig. $5 a$ shows the voltage gain of the two-phase interleaved tappedinductor converter when the converter has inductors with $N=2$. This means that $R_{\mathrm{L} x 2}$ is twice the value of $R_{\mathrm{L} x 1}$, the windings are structurally symmetric and use the same wire. Fig. $5 a$ presents

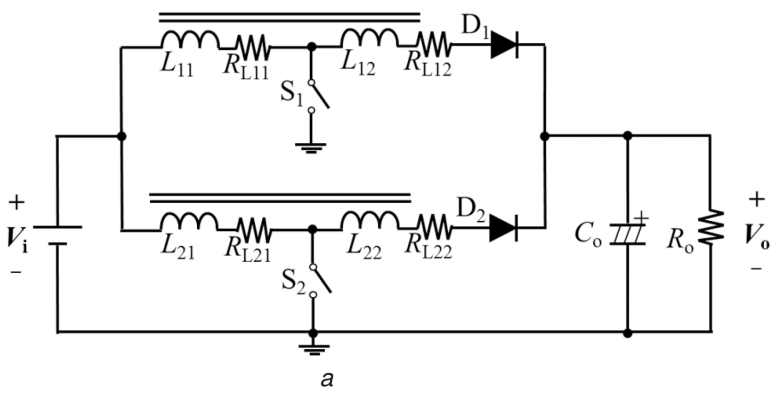

Fig. 4 Interleaved tapped-inductor converter with parasitic resistances (a) Schematic, (b) Mode 1, (c) Mode 2, (d) Mode 3, (e) Mode 4 several voltage gains corresponding to some parasitic resistance ratios between the primary windings and the load $\left(R_{\mathrm{L} 1} / R_{\mathrm{O}}\right)$. It is important to mention that Fig. $5 a$ is obtained using $\left(R_{\mathrm{L} 1}+R_{\mathrm{L} 2}\right) / R_{\mathrm{O}}$ $=3 R_{\mathrm{L} 1} / R_{\mathrm{O}}$.

Now, using the state equations presented above, it is possible to derive the efficiency expression of the two-phase interleaved tapped-inductor converter, shown in (19), when parasitic components are considered

$$
\begin{aligned}
\eta_{\text {tapped }} & =\frac{(1-D)^{2}}{\left(R_{\mathrm{L} 1} / R_{\mathrm{o}}\right) D(1+N)^{2}+\left(\left(R_{\mathrm{L} 1}+R_{\mathrm{L} 2}\right) / R_{\mathrm{o}}\right)(1-D)+(1-D)^{2}} \\
& =\frac{M_{\text {tapped non -ideal }}(1-D)}{(1+N D)}
\end{aligned}
$$

Fig. $5 b$ shows the efficiency plot of the tapped-inductor converter when ratios $R_{\mathrm{L} 1} / R_{\mathrm{O}}$ between 0.1 and 0.000075 are considered.

\section{Super tapped-inductor converter}

Besides the magnetic integration technique, voltage multipliers are used as effective circuits to increase the voltage gain in DC-DC converters. Fig. $1 c$ shows the single-phase tapped-inductor converter with voltage multiplier capacitors proposed in [45] (from now on 'super tapped inductor'). The circuit can achieve a rapid HSU operation, leakage energy recycling to the output terminal, and relatively low-voltage stresses on the components. In addition, it can achieve quite high voltage gains due to its number of capacitors.

The converter has a tapped inductor, as the previous one, composed of two windings $n_{1}$ and $n_{2}$; a main switch $S_{1}$; five diodes $D_{1}-D_{5}$; and five capacitors $C_{1}-C_{4}$ and $C_{0}$. $C_{1,4}$ operate as boosting capacitors, $C_{2,3}$ operate as switched capacitors, and $C_{\mathrm{o}}$ is the output filter capacitor.

The turn ratio $N$ is defined as the rate between the number of turns of $L_{12}$ and $L_{11}$. It is expected that when the turn ratio of the coupled inductor is enlarged, the converter increases its voltage gain. Combining these attractive features and the operating principle, the authors in [45] present the ideal voltage-gain expression according to the duty cycle:

$$
M_{\text {Super }}=\frac{N(2+D)+3}{1-D}
$$

Fig. 6 shows now the super tapped-inductor converter with copper resistances considering the parasitic components in the windings. Similarly to the tapped-inductor converter, this topology has two parasitic resistances: $R_{\mathrm{L} 1}$ and $R_{\mathrm{L} 2}$, one in each winding.

Assuming a symmetrical construction of the windings, i.e. a wire with the same cross-sectional area, it is possible to assume that $R_{\mathrm{L} 2}=N R_{\mathrm{L} 1}$. Considering the steady-state analysis and the subsequent derivation of the voltage gain, the authors in [45] present the voltage gain according to the duty cycle and the parasitic resistance ratio $R_{\mathrm{L} 1} / R_{\mathrm{O}}$ (see (21)) where
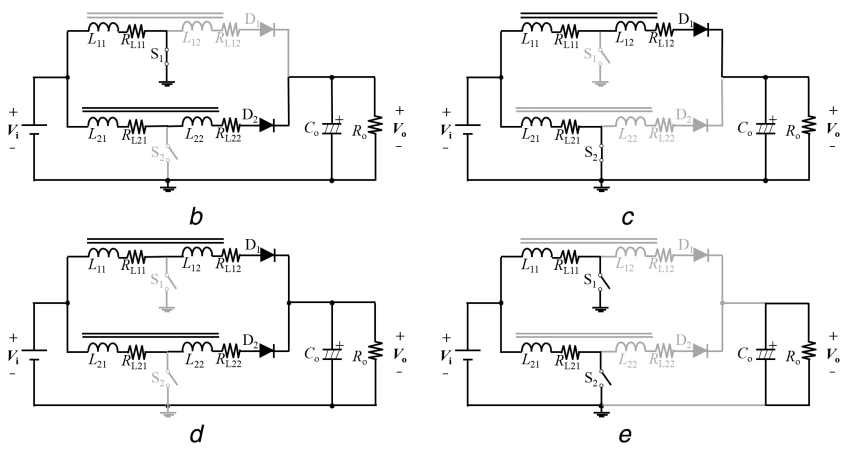

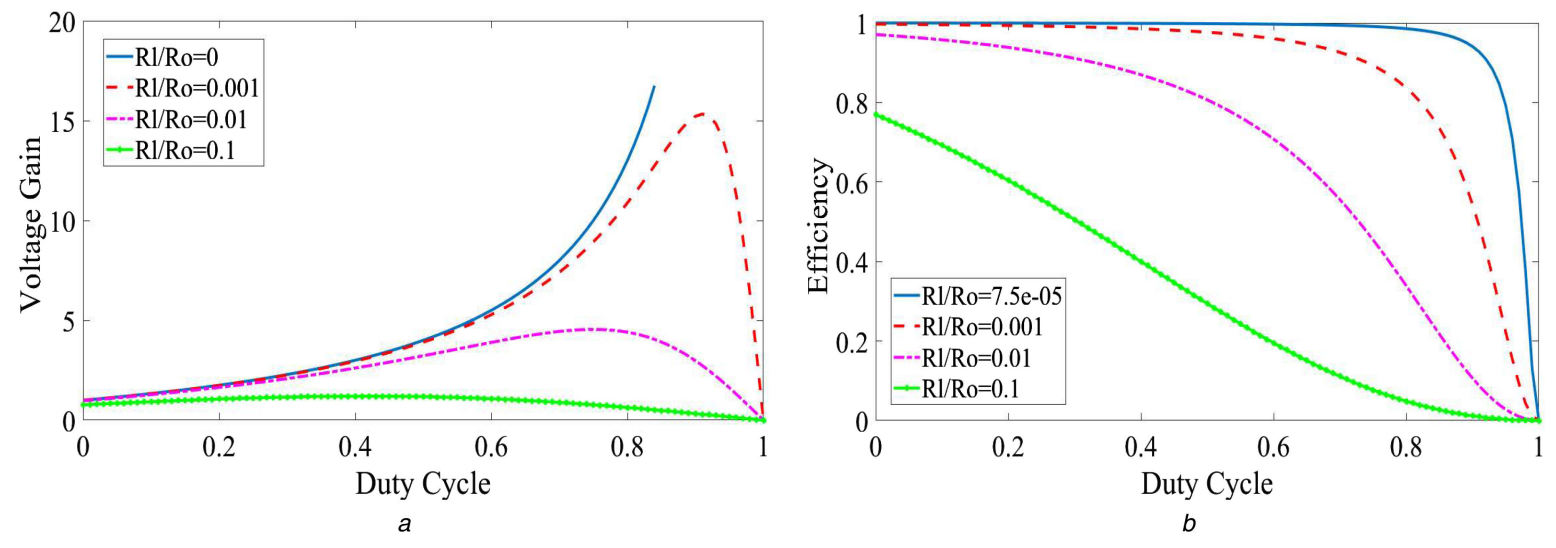

Fig. 5 Non-ideal voltage gain and efficiency of the tapped-inductor converter

(a) Non-ideal voltage gain of the tapped-inductor converter for $R_{\mathrm{L} 1} / R_{\mathrm{O}}=0-0.1$, (b) Efficiency of the tapped-inductor converter for $R_{\mathrm{L} 1} / R_{\mathrm{O}}=0.1-0.000075$

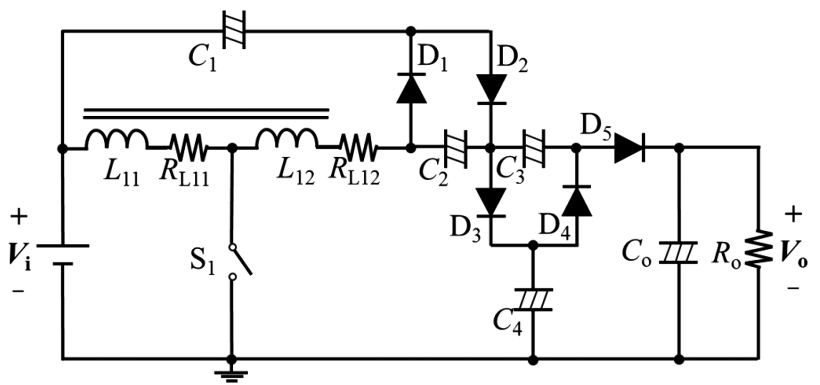

Fig. 6 Super tapped-inductor converter with parasitic resistances

$$
\begin{gathered}
A=N(2+D)+3 \\
B=2 N[N(2+D)+3]
\end{gathered}
$$

From (21), Figs. $7 a$ and $b$ shows the voltage gain of the super tapped-inductor converter when it has a tapped inductor with $N=2$. Fig. $7 a$ presents the voltage gain of the converter with the parasitic resistance ratios evaluated in [45] $\left(R_{\mathrm{L} 1} / R_{\mathrm{O}}=0.0005,0.0001\right.$, and 0.001). Nevertheless, these values correspond to inductors with very small copper resistances (almost ideal) or to very low-power converters (large resistances in the load). Thus, in order to have a better understanding of the parasitic impact on the voltage gain of this converter, Fig. $7 b$ shows the voltage gain evaluated with the same ratios of the other analysed converters $\left(R_{\mathrm{L} 1} / R_{\mathrm{O}}=0,0.001\right.$, 0.01 , and 0.1 ). Note that the evaluations of Fig. 7 are conducted having in mind that $R_{\mathrm{L} 2}=N R_{\mathrm{L} 1}$.

In addition, from [45], (24) shows the efficiency expression of the super tapped-inductor converter when parasitic components are considered. Fig. $7 c$ presents the efficiency considering a range of ratios $R_{\mathrm{L} 1} / R_{\mathrm{O}}$ between 0.001 and 0.000075 , and Fig $7 d$ shows the efficiency cases of $R_{\mathrm{L} 1} / R_{\mathrm{O}}$ between 0.1 and 0.001 (see (24)) .

\section{Interleaved boost converter with IWCI}

Finally, Fig. $1 d$ shows the schematic of the two-phase interleaved HSU converter with the integrated winding coupled-inductor (IWCI) proposed by the authors. This converter has a magnetic coupled-inductor, composed of three windings installed only in one core, and it has been studied in [46]. To achieve the magnetic integration, an EE core is used to install each winding in each leg of the core. The external windings are directly coupled. An air-gap is installed in each external leg in order to suppress DC flux induction. In addition, each external winding, $L_{1}$ and $L_{2}$, is connected to the power source, and the central winding $L_{\mathrm{c}}$ is located between the cathodes of $D_{1}$ and $D_{2}$.
The converter has four diodes $D_{1}-D_{4}$, one output capacitor $C_{0}$, and two power switches $S_{1}$ and $S_{2}$, which are alternatively commuted with a phase difference of $180^{\circ}$ between them.

$N$ is defined as the turn ratio between the central winding $N_{\mathrm{c}}$ and the external windings $N_{\mathrm{e}}$, knowing that $N_{\mathrm{e}}=N_{1}=N_{2}$. This converter has a high voltage gain due to the presence of the central winding in the coupled inductor and its position between the diodes. This central winding is influenced by the magnetic fluxes produced by the external windings that are directly coupled [46].

Furthermore, the IWCI HSU converter has the same components of the two-phase interleaved boost converter, described in Section 2, with the addition of one winding $L_{\mathrm{c}}$ and two output diodes $D_{3}$ and $D_{4}$. As any two-phase interleaved converter, the IWCI HSU converter has two different operating modes (when the duty cycle is lower or higher than $50 \%$ ). Therefore, according to [46], and based on the overall operating principle, the voltage gain for both modes is

$$
\begin{gathered}
M_{\text {IWCI }-D<0.5}=\frac{1+N}{(1+N)-D(1+2 N)} \\
M_{\text {IWCI }-D>0.5}=\frac{1+N}{1-D}
\end{gathered}
$$

Assuming a non-ideal condition where the copper resistances of the three windings are considered, Fig. 8 shows the equivalent circuit of the IWCI converter with parasitic resistances.

Here, $R_{\mathrm{L} 1}, R_{\mathrm{L} 2}$, and $R_{\mathrm{Lc}}$ correspond to the equivalent parasitic resistance in series of each external winding and the central winding, respectively. Therefore, for analytical convenience, it is possible to assume that:

$$
R_{\mathrm{L}}=R_{\mathrm{L} 1}=R_{\mathrm{L} 2}=\frac{R_{\mathrm{Lc}}}{N}
$$

In this context, considering the four operating modes with the copper resistances, it is possible to derive the state equations as follows:

Mode 1

$$
\begin{aligned}
& v_{\mathrm{L} 1}=V_{\mathrm{i}}-i_{\mathrm{L}} R_{\mathrm{L}} \\
& v_{\mathrm{L} 2}=V_{\mathrm{i}}-i_{\mathrm{L}} R_{\mathrm{L}}+v_{\mathrm{Lc}}-i_{\mathrm{L}} R_{\mathrm{Lc}}-V_{\mathrm{o}} \\
& i_{\mathrm{Co}}=i_{\mathrm{L}}-\frac{V_{\mathrm{o}}}{R_{\mathrm{o}}}
\end{aligned}
$$

Mode 2

$$
M_{\text {super non -ideal }}=\frac{((N(2+D)+3) /(1-D))}{1+\left(R_{\mathrm{L} 1} / R_{\mathrm{o}}\right)\left((3(N+1) A) /(1-D)^{2}\right)+\left(\left(2 R_{\mathrm{L} 1} B+R_{\mathrm{L} 2}(4+5 D)\right) /\left(D(1-D) R_{\mathrm{o}}\right)\right)}
$$




$$
\begin{aligned}
\eta_{\text {super }} & =\frac{1}{1+\left(R_{\mathrm{L} 1} / R_{\mathrm{o}}\right)\left((3(N+1) A) /(1-D)^{2}\right)+\left(\left(2 R_{\mathrm{L} 1} B+R_{\mathrm{L} 2}(4+5 D)\right) /\left(D(1-D) R_{\mathrm{o}}\right)\right)} \\
& =\frac{M_{\text {super non -ideal }}}{((N(2+D)+3) /(1-D))}
\end{aligned}
$$$$
v_{\mathrm{L} 1}=V_{\mathrm{i}}-i_{\mathrm{L}} R_{\mathrm{L}}-v_{\mathrm{Lc}}-i_{\mathrm{L}} R_{\mathrm{Lc}}-V_{\mathrm{o}}
$$$$
v_{\mathrm{L} 2}=V_{\mathrm{i}}-i_{\mathrm{L}} R_{\mathrm{L}}
$$$$
i_{\mathrm{Co}}=i_{\mathrm{L}}-\frac{V_{\mathrm{o}}}{R_{\mathrm{o}}}
$$

Mode 4

Mode 3

$$
\begin{aligned}
& v_{\mathrm{L} 1}=v_{\mathrm{i}}-i_{\mathrm{L}} R_{\mathrm{L}}-V_{\mathrm{o}} \\
& v_{\mathrm{L} 2}=v_{\mathrm{i}}-i_{\mathrm{L}} R_{\mathrm{L}}-V_{\mathrm{o}} \\
& i_{\mathrm{Co}}=2 i_{\mathrm{L}}-\frac{V_{\mathrm{o}}}{R_{\mathrm{o}}}
\end{aligned}
$$

$$
\begin{aligned}
& v_{\mathrm{L} 1}=v_{\mathrm{i}}-i_{\mathrm{L}} R_{\mathrm{L}} \\
& v_{\mathrm{L} 2}=v_{\mathrm{i}}-i_{\mathrm{L}} R_{\mathrm{L}} \\
& i_{\mathrm{Co}}=-\frac{V_{\mathrm{o}}}{R_{\mathrm{o}}}
\end{aligned}
$$

Then, combining (28)-(31) and the duty cycle cases, the voltage gain considering the parasitic resistance can be calculated as
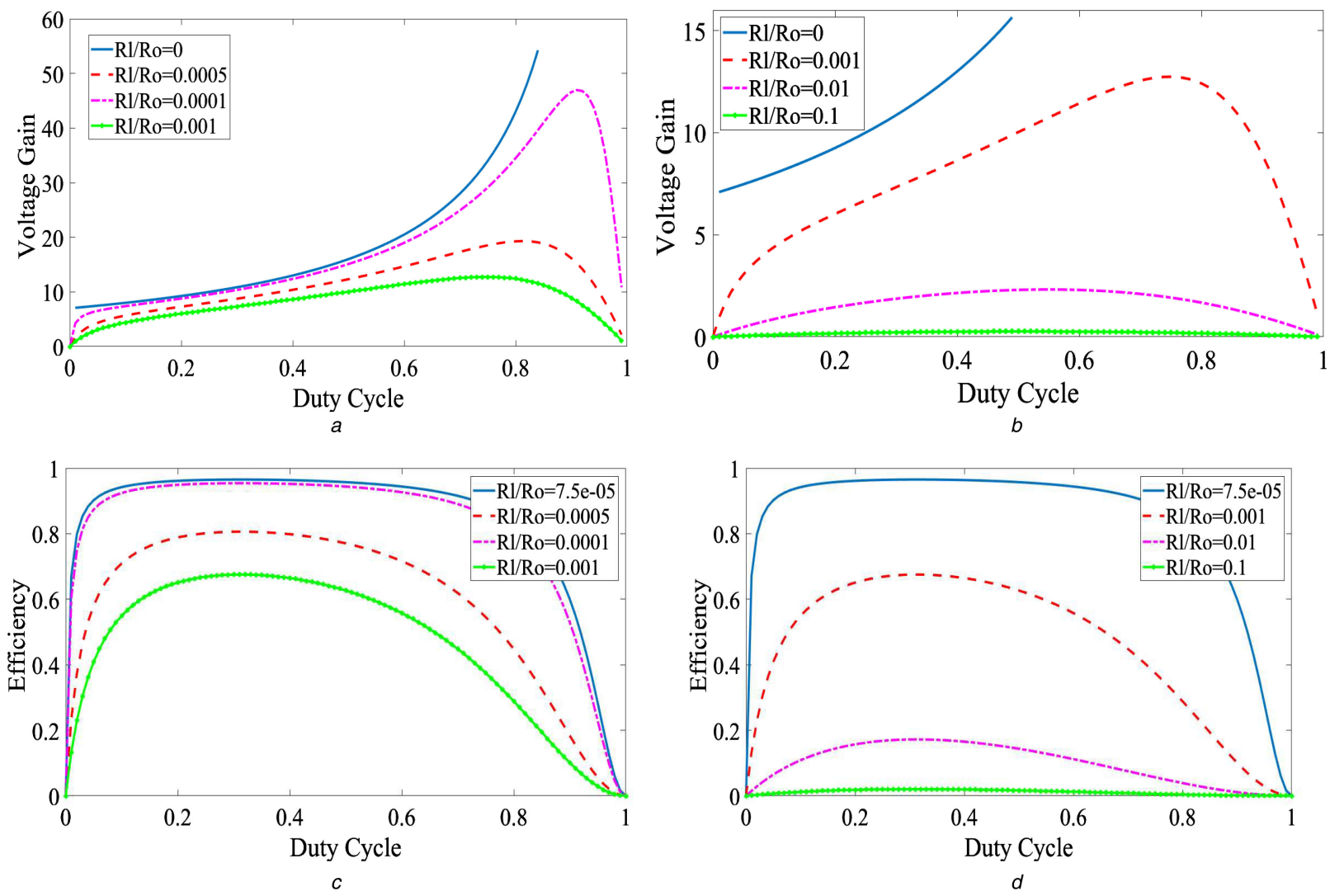

Fig. 7 Voltage gain and efficiency of the super tapped-inductor converter (a) Non-ideal voltage gain of the super tapped-inductor converter for $R_{\mathrm{L} 1} / R_{\mathrm{O}}=0.001-0.0005$, (b) Non-ideal voltage gain of the super tapped-inductor converter for $R_{\mathrm{L} 1} / R_{\mathrm{O}}=0.1-$ 0.001 , (c) Efficiency of the super tapped-inductor converter for $R_{\mathrm{L} 1} / R_{\mathrm{O}}=0.001-0.000075$, (d) Efficiency of the super tapped-inductor converter for $R_{\mathrm{L} 1} / R_{\mathrm{O}}=0.1-0.001$
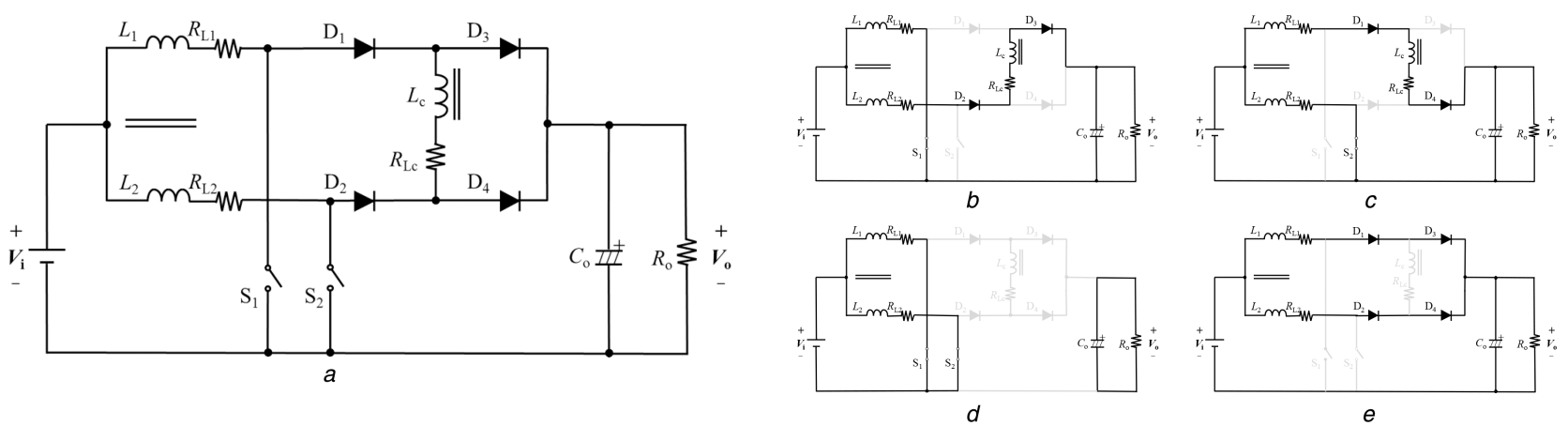

Fig. 8 IWCI converter with parasitic resistances (a) Schematic, (b) Mode 1, (c) Mode 2, (d) Mode 3, (e) Mode 4 


$$
\begin{aligned}
\eta_{\mathrm{IWCI}-D<0.5} & =\frac{1}{[(1+N)-d(1+2 N)]+\left(R_{\mathrm{L}} / R_{\mathrm{o}}\right)(((1+N d)(1+N)) /(2(1-d)))} \\
& =\frac{M_{\mathrm{IWCI}-\text { non }- \text { ideal }-D<0.5}}{1+N}
\end{aligned}
$$

$$
\begin{aligned}
& M_{\mathrm{IWCI}-\text { non }- \text { ideal }-D<0.5} \\
& =\frac{1+N}{[(1+N)-d(1+2 N)]+\left(R_{\mathrm{L}} / R_{\mathrm{o}}\right)(((1+N d)(1+N)) /(2(1-d)))}
\end{aligned}
$$

$$
\begin{aligned}
& M_{\text {IWCI }- \text { non }- \text { ideal }-D>0.5} \\
& =\frac{1+N}{1-d+\left(R_{\mathrm{L}} / R_{\mathrm{o}}\right)(((1+N-N d)(1+N)) /(2(1-d)))}
\end{aligned}
$$

The complete voltage gain for all the duty cycle values is constructed from (32) and (33). Fig. $9 a$ shows the plotted voltage gain of the IWCI converter with a turn ratio $N=2$. Similar to the previous evaluations, several values of the parasitic resistance ratio $R_{\mathrm{L}} / R_{\mathrm{O}}$ were considered.

Now, using the state equations, it is possible to derive the efficiency expression of the super tapped-inductor converter when parasitic components are considered, i.e. (34) and (35). Fig. 9b shows the efficiency of the IWCI converter when several ratios $R_{\mathrm{L}} / R_{\mathrm{O}}$ are evaluated (see (34))

$$
\begin{aligned}
\eta_{\mathrm{IWCI}-D>0.5} & =\frac{1}{1-d+\left(R_{\mathrm{L}} / R_{\mathrm{o}}\right)(((1+N-N d)(1+N)) /(2(1-d)))} \\
& =\frac{M_{\mathrm{IWCI}}-\text { non }- \text { ideal }-D>0.5}{1+N}
\end{aligned}
$$

\section{Voltage gain and efficiency analysis}

With the purpose of evaluating the effectiveness of each converter, voltage gain and efficiency comparisons were made considering the operating principle and the effect of the inductors' copper resistances on each converter described above: The interleaved

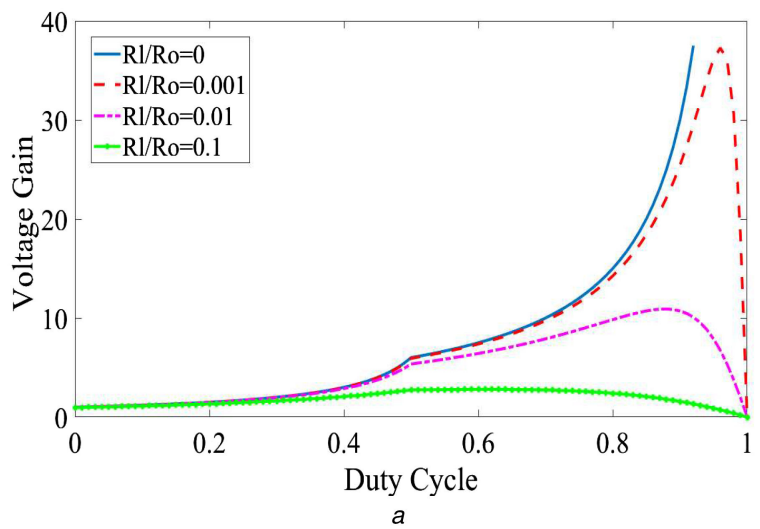

boost converter, the interleaved tapped-inductor converter, the super tapped-inductor converter, and the IWCI HSU converter.

The use of the magnetic coupling technique is evident because each of the studied topologies uses coupled inductors, tapped inductors or integrated coupled inductors, where the common factor is the magnetic integration into only one magnetic core. With the exception of the conventional boost converter, the voltage gain of the studied converters depends on the turn ratio $N$ of the coupled-inductors or tapped inductors.

In summary, Fig. 10 shows the characteristic comparison of the mentioned HSU converters. In this table, the ideal voltage gain, the non-ideal voltage gain (considering the parasitic copper resistances), and the efficiency are compared.

Concerning the voltage-gain response, Fig. $11 a$ shows the ideal voltage-gain behaviour of each converter. This comparison is carried out using a fair evaluation with the same turn ratio, i.e. $N=$ 2. Fig. $11 a$ shows that the super tapped-inductor converter with voltage multiplier capacitors offers the highest voltage gain compared with the one of the other studied converters. This ideal voltage gain is much higher than in the conventional boost converter and almost four times the voltage gain of the IWCI and tapped-inductor converters (for the case of a duty cycle of 0.9 ). The super tapped-inductor converter ideally offers a remarkable performance in all the duty cycle range, while the IWCI HSU converter presents higher voltage gain than the tapped inductor and the conventional boost converter, especially when the duty cycle is higher than 0.5 .

On the other hand, considering that the inductors of these converters present parasitic resistances, it is possible to compare

\begin{tabular}{|c|c|c|c|}
\hline Converter & $r$ Ideal voltage-gain $M$ & Voltage gain with parasitic effects $M$ & Efficiency \\
\hline interleaved & 1 & 1 & 1 \\
\hline boost & $\overline{1-D}$ & $\overline{(1-D)\left(1+\left(R_{\mathrm{L}} /\left(R_{\mathrm{o}}(1-D)^{2}\right)\right)\right)}$ & $\overline{\left(1+\left(R_{\mathrm{L}} /(R(1-D))\right)\right)}$ \\
\hline tapped- & $1+N D$ & $(1+N D)(1-D)$ & $(1-D)$ \\
\hline inductor & $\overline{1-D}$ & $\overline{\left(R_{\mathrm{L} 1} / R_{\mathrm{o}}\right) D(1+N)^{2}+\left(\left(R_{\mathrm{L} 1}+R_{\mathrm{L} 2}\right) / R_{\mathrm{o}}\right)(1-D)+(1-D)^{2}}$ & $\overline{\left(R_{\mathrm{L} 1} / R_{\mathrm{o}}\right) D(1+N)^{2}+\left(\left(R_{\mathrm{L} 1}+R \quad\right) / R\right)(1-D)+(1-D)}$ \\
\hline super & $N(2+D)+3$ & $((N(2+D)+3) /(1-D))$ & 1 \\
\hline $\begin{array}{l}\text { tapped } \\
\text { inductor }\end{array}$ & $1-D$ & $1+\left(R_{\mathrm{L} 1} / R_{\mathrm{o}}\right)\left((3(N+1) A) /\left((1-D)^{2}\right)\right)+\left(\left(2 R_{\mathrm{L} 1} B+R_{\mathrm{L} 2}(4+5 D)\right) /\left(D(1-D) R_{\mathrm{o}}\right)\right)$ & $1+\left(R_{\mathrm{L} 1} / R_{\mathrm{o}}\right)\left((3(N+1) A) /(1-D)^{2}\right)+((2 R \quad B+R(4+5 D)) /(D(1-D) R)$ \\
\hline IWCI & $D<0.5=\frac{1+N}{(1+N)-D(1+2 N)}$ & $D<0.5=\frac{1+N}{[(1+N)-D(1+2 N)]+\left(R_{\mathrm{L}} / R_{\mathrm{o}}\right)(((1+N D)(1+N)) /(2(1-D)))}$ & $D<0.5=\frac{1}{[(1+N)-D(1+2 N)]+(R / R)(((1+N D)(1+N)) /(2(-D)))}$ \\
\hline & $D>0.5=\frac{1+N}{1-D}$ & $D>0.5=\frac{1+N}{1-D+\left(R_{\mathrm{L}} / R_{0}\right)(((1+N-N D)(1+N)) /(2(1-D)))}$ & 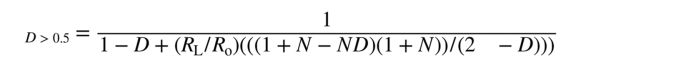 \\
\hline
\end{tabular}
the non-ideal voltage gain of the converters. Fig. $11 b$ presents the non-ideal voltage gain of the four converters evaluated with a turn ratio $N=2$ and $R_{\mathrm{L}} / R_{\mathrm{O}}=0.001\left(R_{\mathrm{L}}=R_{\mathrm{L} 1}\right.$ for the tapped inductors $)$. Fig. $11 c$ shows the case of $R_{\mathrm{L}} / R_{\mathrm{O}}=0.01$.

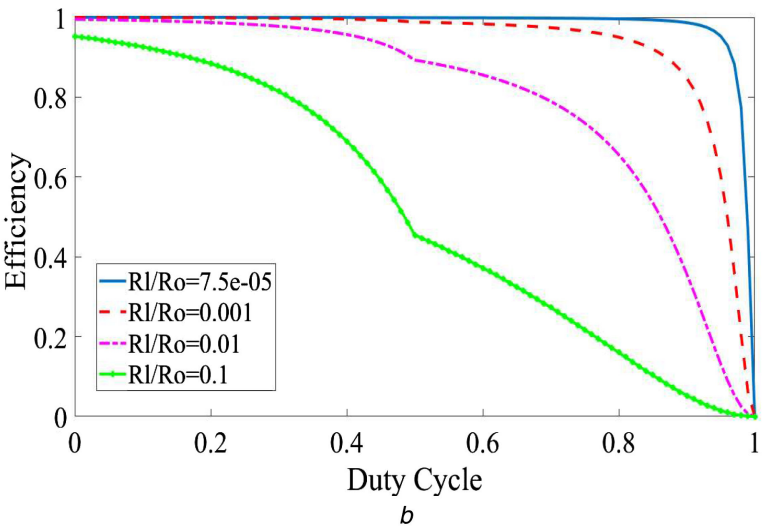

Fig. 9 Voltage gain and efficiency of the IWCI converter

(a) Non-ideal voltage gain of the IWCI converter for $R_{\mathrm{L} 1} / R_{\mathrm{O}}=0.1-0.001$, (b) Efficiency of the IWCI converter for $R_{\mathrm{L} 1} / R_{\mathrm{O}}=0.1-0.000075$

Fig. 10 Converters comparison 

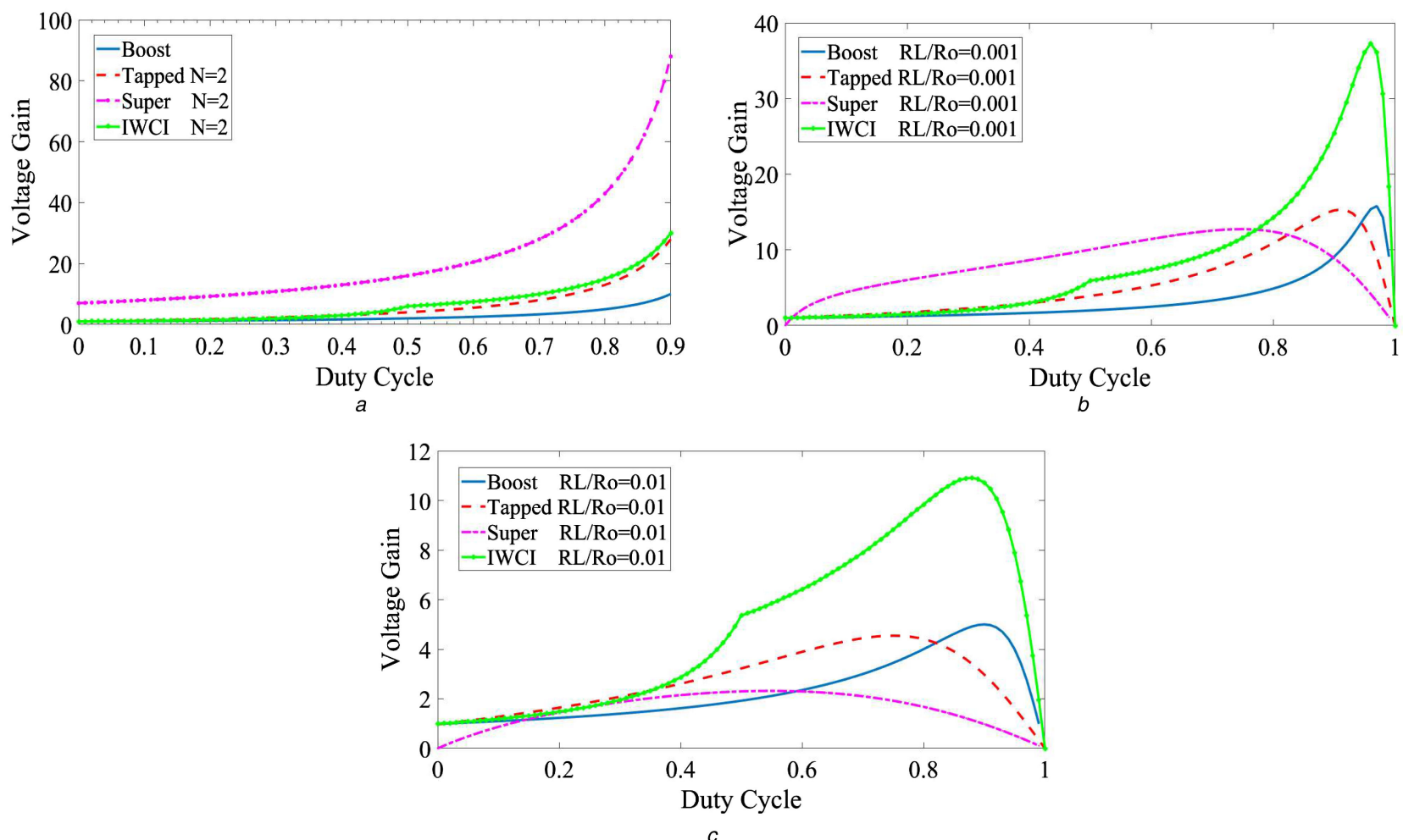

Fig. 11 Voltage-gain comparison of the studied converters

(a) Ideal voltage-gain comparison of the converters, (b) Non-ideal voltage-gain comparison of the converters with $R_{\mathrm{L}} / R_{\mathrm{O}}=0.001$, (c) Non-ideal voltage-gain comparison of the converters with $R_{\mathrm{L}} / R_{\mathrm{O}}=0.01$

Fig. 11 shows a great drawback of the super tapped-inductor converter. Although it presents the highest ideal voltage gain, the presence of many components and the location of the tapped inductor prior the boosting and switched capacitors produce that the copper resistances deteriorate the voltage gain. For these reasons, at a ratio of $R_{\mathrm{L}} / R_{\mathrm{O}}=0.001$, the voltage gains for duty cycles higher than 0.75 decrease rapidly. What is more, there are duty cycles where the super tapped converter presents voltage gains lower than 1. Finally, the case of a ratio of $R_{\mathrm{L}} / R_{\mathrm{O}}=0.01$ reveals the great impact of the copper resistance on the voltage gain of the super tapped converter. As shown in Fig. 11c, the voltage gain for the super tapped converter is $<1$ for many duty cycles, making it a step-down converter rather than an HSU converter under those circumstances.

On the contrary, it is evident the good voltage gain of the IWCI converter for several $R_{\mathrm{L}} / R_{\mathrm{o}}$ ratios because it achieves much higher voltage gain than the other converters, especially when the copper resistance increases or when the converter power increases as well. Note that the IWCI HSU converter always presents higher voltage gain than the tapped-inductor converter and the conventional boost converter at all the ratios $R_{\mathrm{L}} / R_{\mathrm{O}}$, and higher than the super tapped converter at ratios higher than 0.01 .

In the same way, Fig. 12 shows the efficiency evaluation of the four converters at several values of $R_{\mathrm{L}} / R_{\mathrm{O}}$. Fig. $12 a$ presents the comparison at the evaluation parameters of [45], where an $R_{\mathrm{L}} / R_{\mathrm{O}}$ ratio of 0.000075 is validated. Fig. $12 b$ shows the case of a ratio of $R_{\mathrm{L}} / R_{\mathrm{O}}=0.001$, and Fig. $12 c$ shows the case of $R_{\mathrm{L}} / R_{\mathrm{O}}=0.01$.

As can be seen from Fig. 12, the IWCI converter has a better efficiency performance than the tapped and the super tapped converter in all the duty cycle cases. In addition, it is evident how the conventional boost converter presents the best efficiency performance in all the cases. This is due to the basic topology and the few components that the converter has.

From these results, the IWCI converter, proposed by the authors, offers suitable characteristics of high voltage-gain, high efficiency, and a relatively simple construction. Therefore, it is possible to state that IWCI converter is a promising topology to be applied in electric mobility or renewable energy applications, capable of sustaining high voltage gain and high efficiency at different loads and different parasitic conditions.

\section{Experimental validation}

Experimental tests of a $100 \mathrm{~W}$ prototype of the IWCI converter are introduced as a validation of the parasitic analysis presented above. These tests were conducted with different loads in order to obtain several ratios of $R_{\mathrm{L}} / R_{\mathrm{O}}$. The prototype is also tested with a wide range of input voltages with the purpose of getting several points of duty cycle and thereby several voltage gains can be obtained. Fig. 13 shows the experimental setup of the selected converter.

This prototype was constructed using silicon carbide diodes, super junction transistors, electrolytic capacitors, and a TDK PC40 ferrite core with three windings and a turn ratio of $N=2$. These components were selected based on their high-efficiency characteristics. The prototype was tested with the parameters of Table 1, where different loads were installed and driven at the same output power in order to obtain all the voltage gains and different duty cycles under a fair comparison.

Fig. $14 a$ shows the experimental results of the prototype at four different conditions of $R_{\mathrm{L}} / R_{\mathrm{O}}$ in comparison with the theoretical ideal performance (without parasitic resistance) of the IWCI converter with $N=2$. This figure validates the effect of the parasitic resistance of the coupled-inductor windings on the voltage-gain performance.

Figs. $14 b-e$ show the experimental results of the prototypes with ratios of $R_{\mathrm{L}} / R_{\mathrm{O}}=0.004,0.005,0.007$, and 0.011 , as well as the theoretical non-ideal values obtained from (32) and (33). The ideal performance of the proposed converter, when the parasitic resistance presented in the coupled inductor is not considered, is also shown in those figures. The experimental results and the theoretical non-ideal values present an average standard error of $0.17,0.19,0.18$, and $0.2 \%$ for ratios of $R_{\mathrm{L}} / R_{\mathrm{O}}=0.004,0.005,0.007$, and 0.011 , respectively.

Additionally, in order to evaluate the efficiency derivation of the IWCI converter, efficiency tests were conducted. These efficiency tests were carried out with a Yokogawa PZ4000 power analyser. Fig. 15 shows the complete set of efficiency 

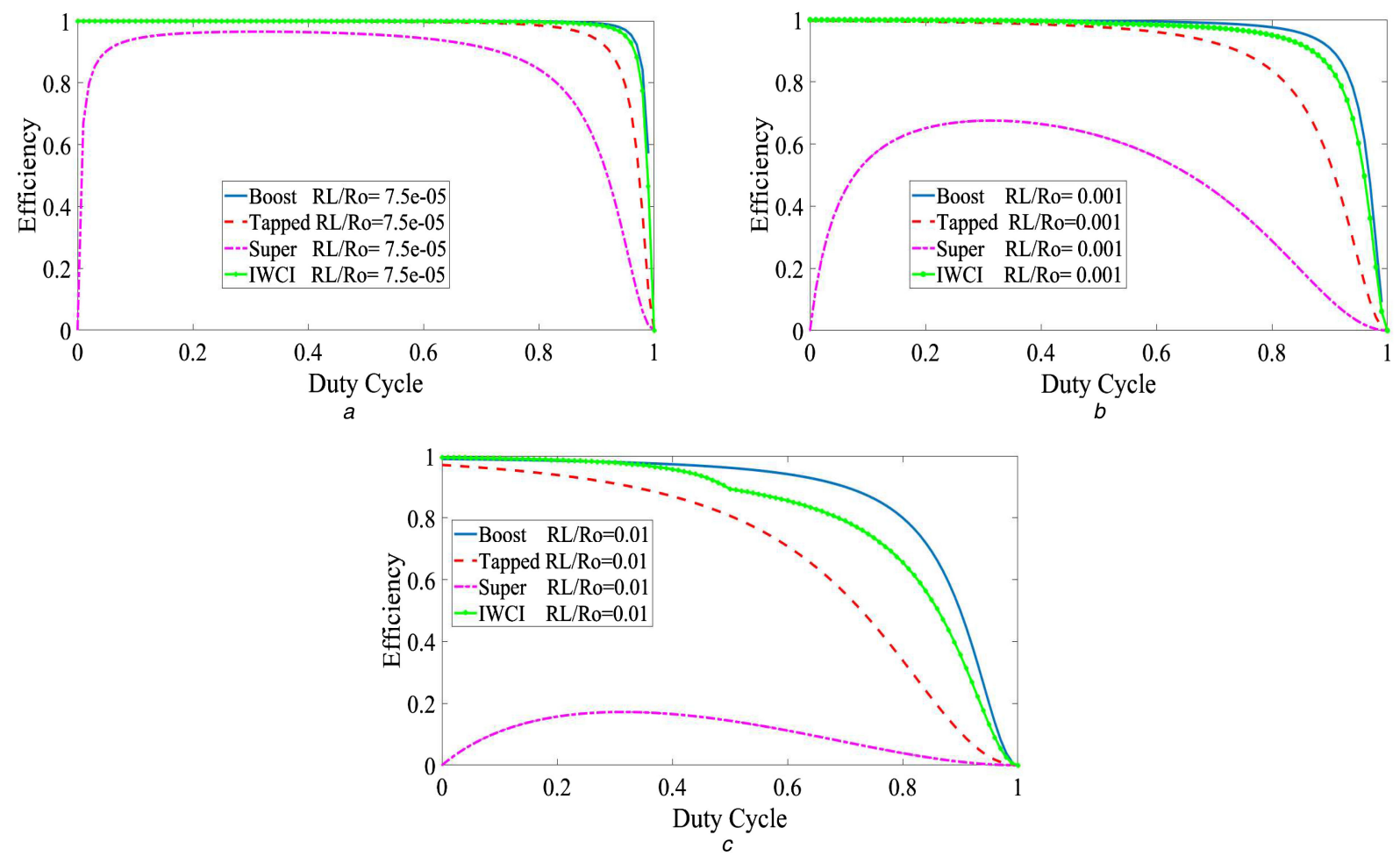

Fig. 12 Efficiency comparison of the studied converters

(a) Efficiency comparison of the converters with $R_{\mathrm{L}} / R_{\mathrm{O}}=0.000075$, (b) Efficiency comparison of the converters with $R_{\mathrm{L}} / R_{\mathrm{O}}=0.001$, (c) Efficiency comparison of the converters with $R_{\mathrm{L}} / R_{\mathrm{O}}=0.01$

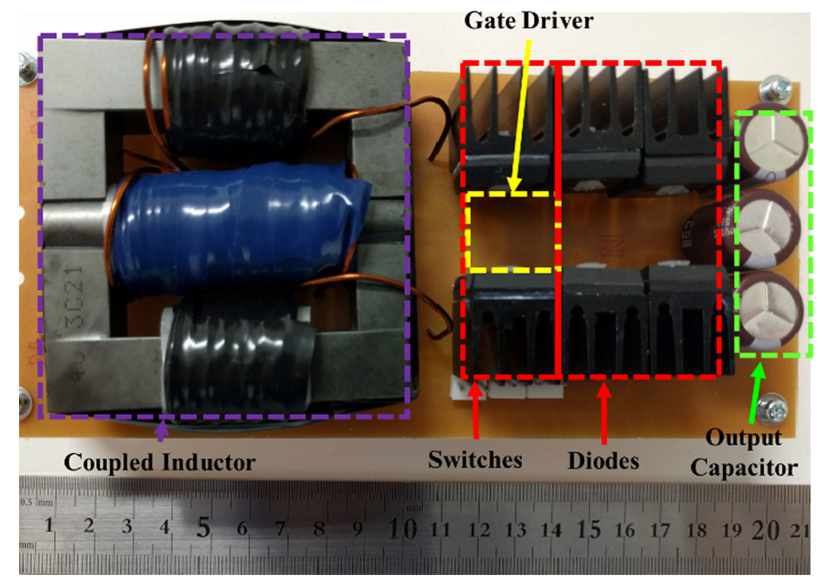

Fig. 13 Experimental setup of the IWCI HSU converter

Table 1 Experimental parameters

\begin{tabular}{|c|c|c|c|c|c|}
\hline resistance ratio & $R_{\mathrm{L}} / R_{\mathrm{O}}$ & 0.0035 & 0.0045 & 0.0071 & 0.0106 \\
\hline load & $R_{\mathrm{O}}$ & $200 \Omega$ & $154.8 \Omega$ & $98.8 \Omega$ & $65.8 \Omega$ \\
\hline input voltage & $v_{\mathrm{i}}$ & $110.3-8.5 \mathrm{~V}$ & $97.5-8.04 \mathrm{~V}$ & $78.9-7.44 \mathrm{~V}$ & $65.5-7.2 \mathrm{~V}$ \\
\hline output voltage & $v_{0}$ & $140 \mathrm{~V}$ & $122.94 \mathrm{~V}$ & $98.08 \mathrm{~V}$ & $79.99 \mathrm{~V}$ \\
\hline output power & $w$ & $98.98 \mathrm{~W}$ & $98.43 \mathrm{~W}$ & $98.24 \mathrm{~W}$ & $97.38 \mathrm{~W}$ \\
\hline frequency & $f$ & \multicolumn{4}{|c|}{$30 \mathrm{kHz}$} \\
\hline number of turns & $N$ & \multicolumn{4}{|c|}{$\begin{array}{l}\text { external: } 16 \text { turns } \\
\text { centre: } 32 \text { turns }\end{array}$} \\
\hline \multirow[t]{3}{*}{ inductance } & $L$ & \multicolumn{4}{|c|}{$L_{1}: 378 \mu \mathrm{H}$} \\
\hline & & \multicolumn{4}{|c|}{$L_{2}: 380 \mu \mathrm{H}$} \\
\hline & & \multicolumn{4}{|c|}{$L_{c}: 1.87 \mathrm{mH}$} \\
\hline \multirow[t]{3}{*}{ parasitic resistance } & $R$ & \multicolumn{4}{|c|}{$R_{\mathrm{L} 1}: 698 \mathrm{~m} \Omega$} \\
\hline & & \multicolumn{4}{|c|}{$R_{\mathrm{L} 2}: 702 \mathrm{~m} \Omega$} \\
\hline & & \multicolumn{4}{|c|}{$R_{\mathrm{Lc} c}: 1.41 \Omega$} \\
\hline
\end{tabular}



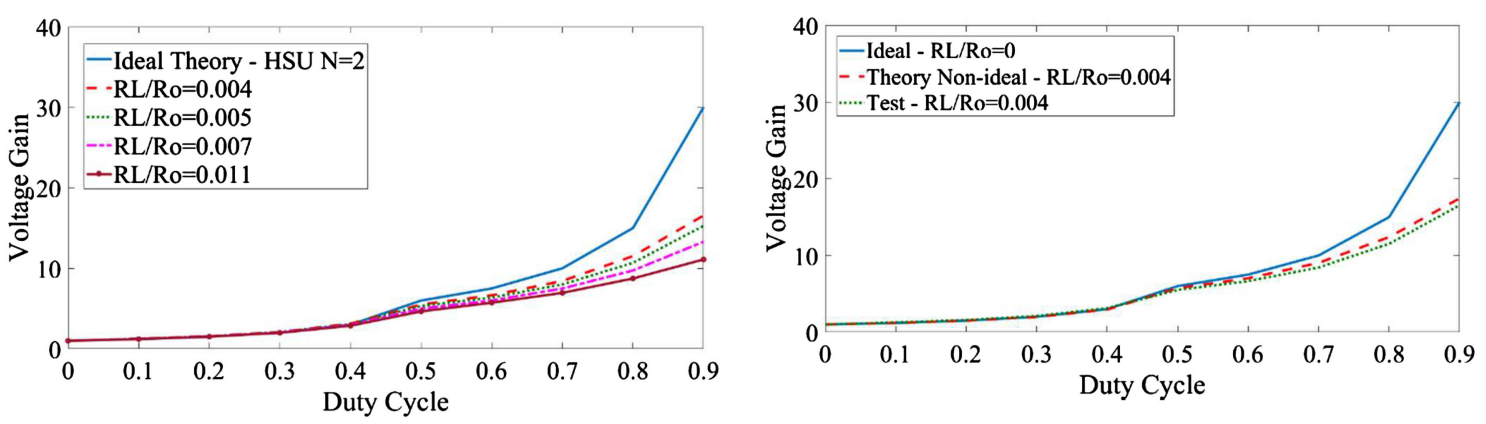

a

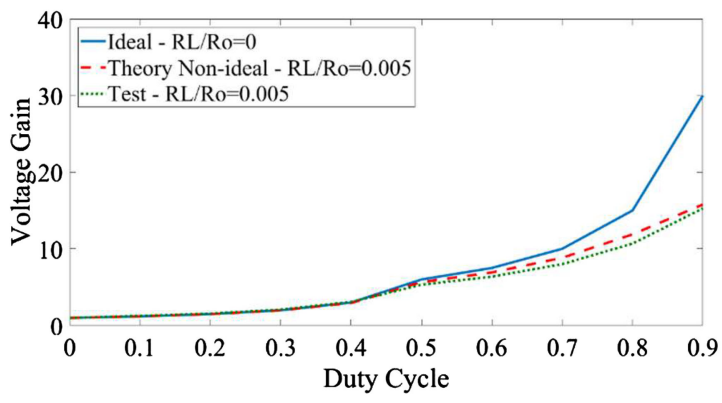

$b$

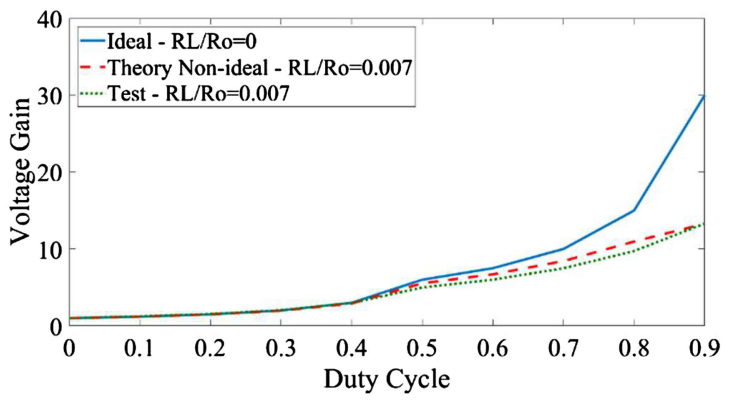

c

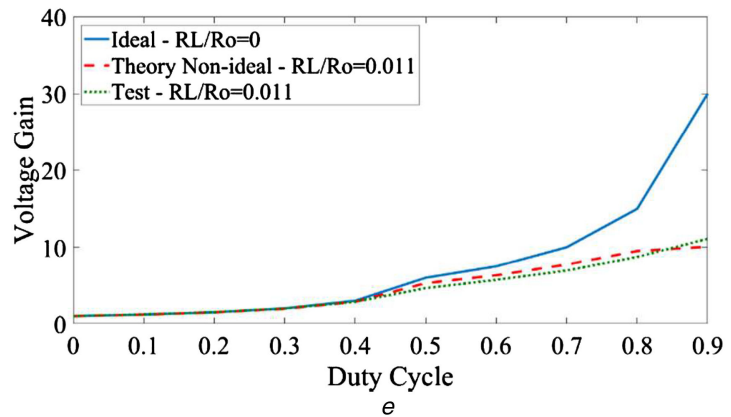

$d$

Fig. 14 Measured voltage gain versus duty cycle

(a) Voltage gain at different ratios $R_{\mathrm{L}} / R_{\mathrm{O}}$, (b) Ideal, theoretical and tested performance with $R_{\mathrm{L}} / R_{\mathrm{O}}=0.004$, (c) Ideal, theoretical and tested performance with $R_{\mathrm{L}} / R_{\mathrm{O}}=0.005$, (d) Ideal, theoretical and tested performance with $R_{\mathrm{L}} / R_{\mathrm{O}}=0.007$, (e) Ideal, theoretical and tested performance with $R_{\mathrm{L}} / R_{\mathrm{O}}=0.011$

measurements of the prototype of Fig. 13 at the same ratios of $R_{\mathrm{L}} / R_{\mathrm{o}}$ presented in Fig. 14. Figs. $15 b-e$ show the experimental results of the prototypes with ratios of $R_{\mathrm{L}} / R_{\mathrm{O}}=0.004,0.005,0.007$, and 0.011 , as well as the calculated efficiency values obtained from (34) and (35). The experimental results and the calculated values present an average standard error of $0.54,0.74,1.13$, and $1.34 \%$ for ratios of $R_{\mathrm{L}} / R_{\mathrm{O}}=0.004,0.005,0.007$, and 0.011 , respectively.

Finally, experimental waveforms of the case d of Figs. 14 and 15 , corresponding to the ratio $R_{\mathrm{L}} / R_{\mathrm{O}}=0.007$, are presented in Fig. 16. This figure shows both cases of duty cycle higher and lower than $50 \%$. As it was explained above, the IWCI converter has different behaviour at different duty cycles. From Fig. 16, it is possible to see the winding current shapes of both duty cycle cases that are characteristic of the IWCI converter as it is presented in [46].

\section{Conclusion}

This paper presents an analysis of the parasitic effect of the copper resistance, presented in the coupled inductors, on the voltage gain and the efficiency of four HSU converters. This study is performed on the base of the operating principle of the conventional twophase interleaved boost converter with coupled inductors, which uses the techniques of interleaving phases and magnetic integration. These techniques have been reported to be effective for downsizing power converters and therefore for being applied in EV or HEV.

From this study, it was confirmed that parasitic resistances presented in the windings of the coupled inductors have a great impact on the voltage gain and the efficiency. Especially, it was observed that a converter with a large number of components increases the probability of parasitic resistance negative effect on the voltage gain and the efficiency. It was the case of the super tapped-inductor converter with voltage multiplier capacitors that offers the highest ideal voltage gain in all the duty cycle range. However, when the copper resistance is considered, its voltage gain and efficiency are highly decreased as the parasitic resistance increases or the load resistance decreases.

In addition, the IWCI HSU converter was found as the topology with the best voltage-gain performance with a good efficiency when the copper resistance is considered, especially at high ratios of $R_{\mathrm{L}} / R_{\mathrm{O}}$. The IWCI HSU presents a reliable voltage gain, even at hard conditions (like a ratio of $R_{\mathrm{L}} / R_{\mathrm{O}}=0.01$ ).

Finally, several experimental tests of a $100 \mathrm{~W}$ prototype of the IWCI HSU converter were performed as a validation of the parasitic analysis of the IWCI HSU converter. Five ratios of $R_{\mathrm{L}} / R_{\mathrm{O}}$ were tested and it was found a maximum average deviation error of $0.2 \%$ in the voltage-gain tests of the IWCI HSU prototype with $N$ $=2$ and $R_{\mathrm{L}} / R_{\mathrm{O}}=0.011$, as well as a maximum average deviation error of $1.34 \%$ in the efficiency tests of the same prototype.

Considering the evaluation of ideal and non-ideal voltage gain, and efficiency of the studied topologies, it is possible to conclude that the IWCI HSU converter is a suitable combination between high voltage gain, and efficiency, and thereby it is a promising topology to be applied in electric mobility and renewable energy applications. 

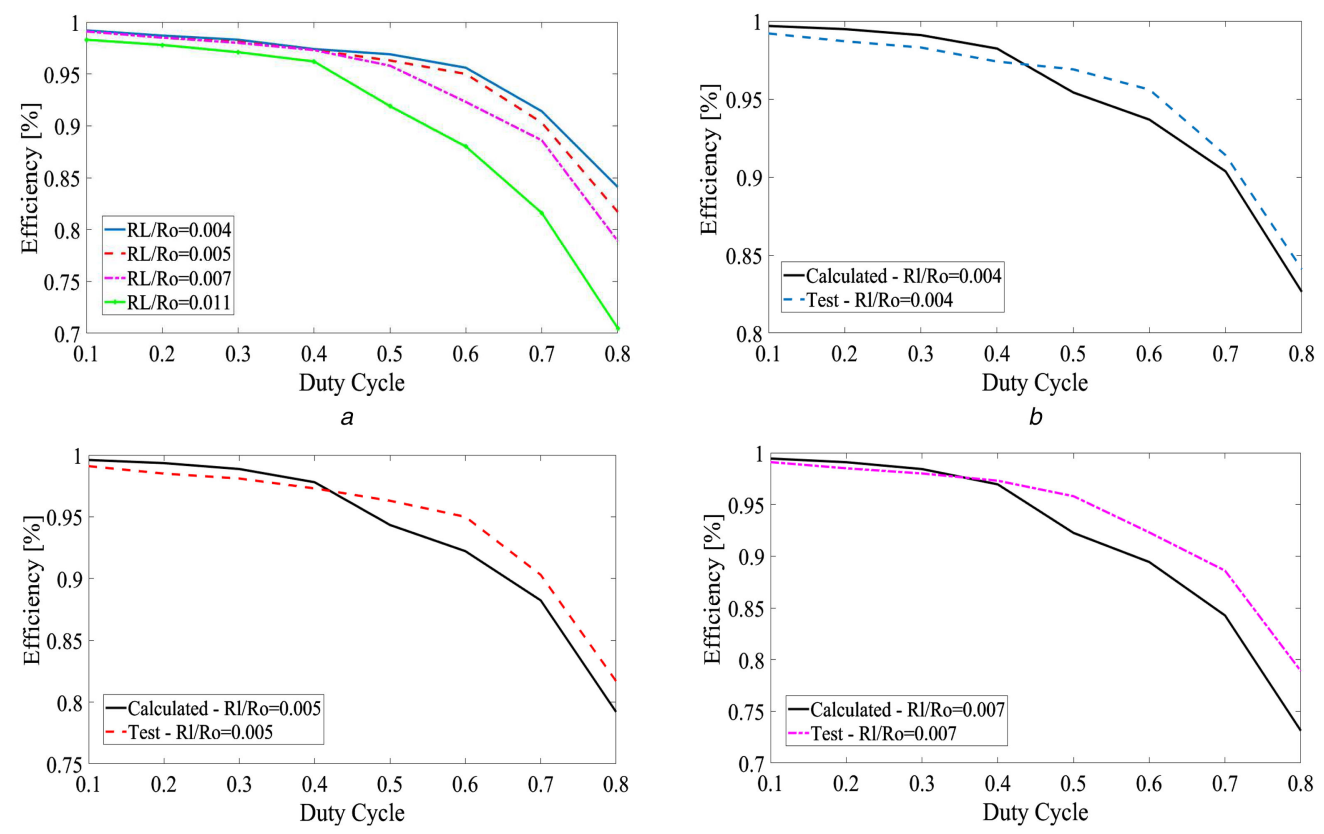

$c$

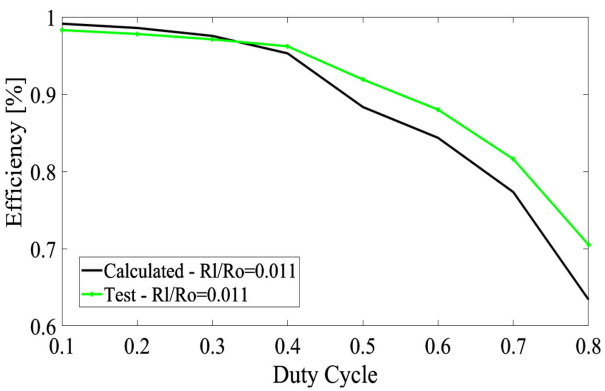

Fig. 15 Measured efficiency versus duty cycle

(a) Efficiency at different ratios $R_{\mathrm{L}} / R_{\mathrm{O}}$, (b) Calculated and tested efficiency with $R_{\mathrm{L}} / R_{\mathrm{O}}=0.004$, (c) Calculated and tested efficiency with $R_{\mathrm{L}} / R_{\mathrm{O}}=0.005$, (d) Calculated and tested efficiency with $R_{\mathrm{L}} / R_{\mathrm{O}}=0.007$, (e) Calculated and tested efficiency with $R_{\mathrm{L}} / R_{\mathrm{O}}=0.011$
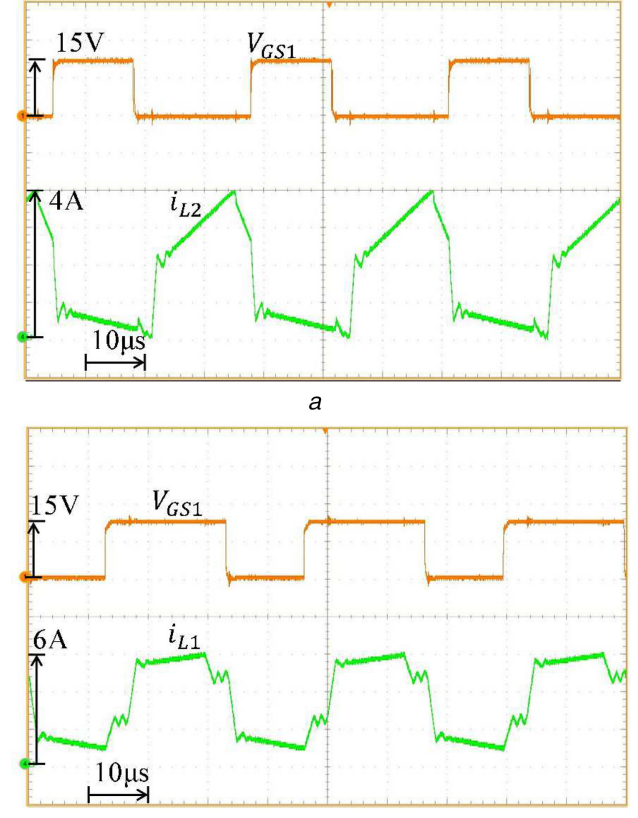

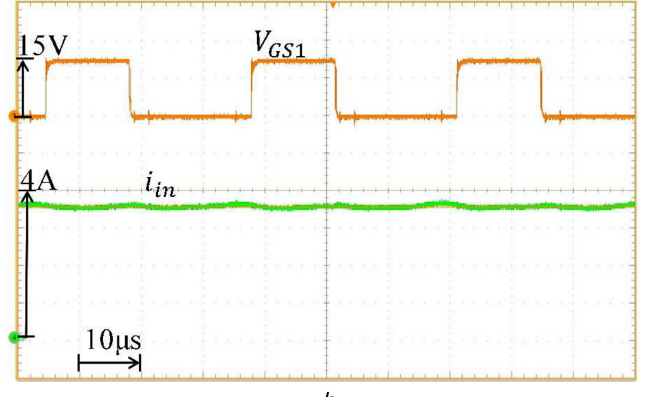

$b$

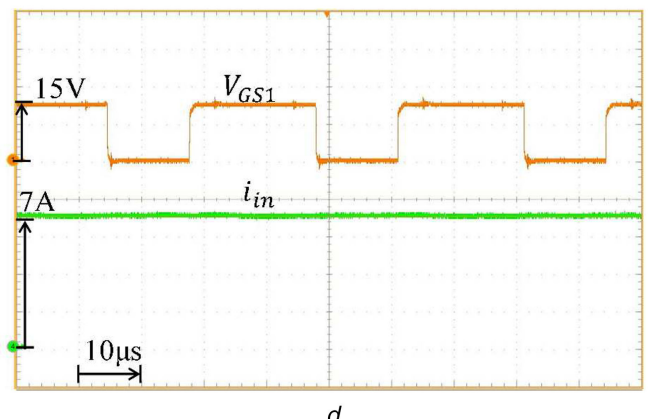

$d$

Fig. 16 Experimental waveforms of the IWCI converter with $R_{L} / R_{O}=0.007$

(a) Gate-source voltage of $S_{1}$ and inductor current of winding $L_{2}$ at $d=40 \%$, (b) Gate-source voltage of $S_{1}$ and input current at $d=40 \%$, (c) Gate-source voltage of $S_{1}$ and input current of winding $L_{1}$ at $d=60 \%$, (d) Gate-source voltage of $S_{1}$ and input current at $d=60 \%$ 


\section{References}

[1] Zhang, S., Zhang, C., Xiong, R., et al.: 'Study on the optimal charging strategy for lithium-ion batteries used in electric vehicles', Energies, 2014, 7, (10), pp. 6783-6797

[2] Bryan, F.J., Forsyth, A.J.: 'A power dense DC-DC converter for a small electric vehicle'. 6th IET Int. Conf. Power Electronics Machines Drives (PEMD 2012), 2012, pp. A31-A31

[3] Yilmaz, M., Krein, P.T.: 'Review of battery charger topologies, charging power levels, and infrastructure for plug-in electric and hybrid vehicles', IEEE Trans. Power Electron., 2013, 28, (5), pp. 2151-2169

[4] Martinez, W., Cortes, C.A., Munoz, L.E et al. 'Desion of a $200 \mathrm{~kW}$ electric powertrain for a high performance electric vehicle', Ing. Investig., 2016, 36, (3), pp. 66-73

[5] Tian, Y., Chen, C., Xia, B., et al:: 'An adaptive gain nonlinear observer for state of charge estimation of lithium-ion batteries in electric vehicles', Energies, 2014, 7, (9), pp. 5995-6012

[6] Aharon, I., Kuperman, A.: 'Topological overview of powertrains for batterypowered vehicles with range extenders', IEEE Trans. Power Electron., 2011, 26, (3), pp. 868-876

[7] Bonfiglio, C., Roessler, W. 'A cost optimized battery management system with active cell balancing for lithium ion battery stacks'. 2009 IEEE Vehicle Power and Propulsion Conf., 2009, pp. 304-309

[8] Lai, C.M.: 'Development of a novel bidirectional DC/DC converter topology with high voltage conversion ratio for electric vehicles and DC-microgrids', Energies, 2016, 9, (6), pp. 1-25

[9] Bashash, S., Moura, S.J., Fathy, H.K.: 'Charge trajectory optimization of plug-in hybrid electric vehicles for energy cost reduction and battery health enhancement'. Am. Control Conf. (ACC), 2010, 2010, pp. 5824-5831

[10] Jin, F., Shin, K.G.: 'Pack sizing and reconfiguration for management of largescale batteries'. Proc. 2012 IEEE/ACM 3rd Int. Conf. Cyber-Physical Systems ICCPS 2012, 2012, pp. 138-147

[11] Engineering, M., Guo, P., Liu, P.: 'Research on development of electric vehicles in China'. 2010 Int. Conf. Future Information Technology and Management Engineering Research, 2010, pp. 94-96

[12] Burress, T., Campbell, S., Coomer, C., et al.: 'Evaluation of the 2010 Toyota Prius hybrid synergy drive system', Technical report, doi:10.2172/1007833 March 2011

[13] Martinez, W., Yamamoto, M., Imaoka, J., et al.: 'Efficiency optimization of a two-phase interleaved boost DC-DC converter for electric vehicle applications'. 2016 IEEE 8th Int. Power Electronics and Motion Control Conf., IPEMC-ECCE Asia 2016, 2016, pp. 2474-2480

[14] Klumpner, C., Ponggorn, K., Rashed, M., et al.: 'Modelling and control of a multi-stage interleaved DC-DC converter with coupled inductors for supercapacitor energy storage system', IET Power Electron., 2013, 6, (7), pp. $1360-1375$

[15] Li, W., Liu, J., Wu, J., et al.: 'Design and analysis of isolated ZVT boost converters for high-efficiency and high-step-up applications', IEEE Trans. Power Electron., 2007, 22, (6), pp. 2363-2374

[16] Li, W., He, X.: 'ZVT interleaved boost converters for high-efficiency, high step-up DC-DC conversion', IET Electr. Power Appl., 2007, 1, (2), p. 284

[17] Park, K.-B., Moon, G.-W., Youn, M.-J.: 'Nonisolated high step-up stacked converter based on boost-integrated isolated converter', IEEE Trans. Power Electron., 2011, 26, (2), pp. 577-587

[18] Munoz, L.E., Blanco, J.C., Barreto, J.P., et al.: 'Conceptual design of a hybrid electric off-road vehicle'. 2012 IEEE Int. Electric Vehicle Conf., 2012, pp. 18

[19] Luk, P.C.K., Rosario, L.C.: 'Power and energy management of a dual-energy source electric vehicle - policy implementation issues'. Conf. Proc. - IPEMC 2006 CES/IEEE 5th Int. Power Electronics Motion Control Conf., 2007, vol. 1 , pp. 464- 468

[20] Ivanovic, Z., Blanusa, B., Knezic, M.: 'Power loss model for efficiency improvement of boost converter'. 2011 XXIII Int. Symp. Information, Communication and Automation Technologies, 2011, pp. 1-6

[21] Imaoka, J., Kimura, S., Itoh, Y., et al.: 'Feasible evaluations of coupled multilayered chip inductor for POL converters', IEE J. Ind. Appl., 2015, 4, (3), pp. 126-135

[22] Shi, Z.H., Ho, S.L., Cheng, K.W.E.: 'Static performance and parasitic analysis of tapped-inductor converters', IET Power Electron., 2014, 7, (2), pp. 366375

[23] Tseng, K.-C., Huang, C.-C.: 'High step-up high-efficiency interleaved converter with voltage multiplier module for renewable energy system', IEEE Trans. Ind. Electron., 2014, 61, (3), pp. 1311-1319

[24] Li, W., Li, W., Cui, W., et al.: 'Interleaved high step-up converter with built-in transformer and voltage doubler for PV grid-connected generation systems keywords'. 14th European Conf. Power Electronics and Applications, 2011, pp. $1-10$

[25] Li, W., Xiang, X., Li, C., et al.: 'Interleaved high step-up ZVT converter with built-in transformer voltage doubler cell for distributed PV generation system', IEEE Trans. Power Electron., 2013, 28, (1), pp. 300-313

[26] Hegazy, O., Van Mierlo, J., Lataire, P.: 'Analysis, modeling, an implementation of a multidevice interleaved DC/DC converter for fuel cell hybrid electric vehicles', IEEE Trans. Power Electron., 2012, 27, (11), pp. 4445-4458

[27] Velandia, F., Martinez, W., Cortes, C.A., et al.: 'Power loss analysis of multiphase and modular interleaved boost DC-DC converters with coupled inductor for electric vehicles'. 2016 18th European Conf. Power Electronics and Applications (EPE'16 ECCE Europe), 2016, pp. 1-10

[28] Hirakawa, M., Nagano, M., Watanabe, Y., et al.: 'High power density DC/DC converter using the close-coupled inductors'. 2009 IEEE Energy Conversion Congress and Exposition, September 2009, pp. 1760-1767

[29] Imaoka, J., Ishikura, Y., Kawashima, T., et al: 'Optimal design method for interleaved single-phase PFC converter with coupled inductor'. 2011 IEEE Energy Conversion Congress and Exposition, 2011, pp. 1807-1812

[30] Adib, E., Poorali, B., Esteki, M., et al.: 'High step-down interleaved buck converter with low voltage stress', IET Power Electron., 2015, 8, (12), pp. 2352-2360

[31] Ho, C.N.M., Breuninger, H., Pettersson, S., et al.: 'Practical design and implementation procedure of an interleaved boost converter using $\mathrm{SiC}$ diodes for PV applications', IEEE Trans. Power Electron., 2012, 27, (6), pp. 2835 2845

[32] Josias de Paula, W., de S. Oliveira Júnior, D., de C. Pereira, D., et al.: 'Survey on non-isolated high-voltage step-up dc-dc topologies based on the boost converter', IET Power Electron., 2015, 8, (10), pp. 2044-2057

[33] Lai, C.M., Lin, Y.C., Lee, D.: 'Study and implementation of a two-phase interleaved bidirectional DC/DC converter for vehicle and DC-microgrid systems', Energies, 2015, 8, (9), pp. 9969-9991

[34] Tseng, S.Y., Ou, C.L., Peng, S.T., et al.: 'Interleaved coupled-inductor boost converter with boost type snubber for PV system'. 2009 IEEE Energy Conversion Congress and Exposition ECCE 2009, 2009, pp. 1860-1867

[35] Araújo, S.V., Bascopé, R.P.T., Bascopé, G.V.T., et al.: 'Step-up converter with high voltage-gain employing three-state switching cell and voltage multiplier'. PESC Record - IEEE Annual Power Electronics Specialists Conference, 2008, pp. 2271-2277

[36] Zhu, J., Pratt, A.: 'Capacitor ripple current in an interleaved PFC converter'. PESC Record - IEEE Annual Power Electronics Specialists Conference, 2008, vol. 24, no. 6, pp. 3444-3450

[37] Yang, F., Ruan, X., Yang, Y., et al.: 'Interleaved critical current mode boost PFC converter with coupled inductor', IEEE Trans. Power Electron., 2011, 26, (9), pp. 2404-2413

[38] Arango, E., Ramos-Paja, C., Calvente, J., et al.: 'Asymmetrical interleaved DC/DC switching converters for photovoltaic and fuel cell applications-part 1: circuit generation, analysis and design', Energies, 2012, 5, (12), pp. 4590 4623

[39] Rylko, M.S., Hartnett, K.J., Hayes, J.G., et al.: 'Magnetic material selection for high power high frequency inductors in DC-DC converters'. 2009 TwentyFourth Annual IEEE Applied Power Electronics Conf. and Exposition, 2009, pp. 2043-2049

[40] Gu, Y., Zhang, D., Zhao, Z: 'Input current ripple cancellation technique for boost converter using tapped inductor', IEEE Trans. Ind. Electron., 2014, 61, (10), pp. 5323-5333

[41] Ramos, N.C.B., Escoto, M.T., Odulio, C.M.F.: 'Design and analysis of an interleaved tapped-inductor boost converter for higher power and voltage-gain applications'. TENCON 2012 IEEE Region 10 Conf., 2012, pp. 1-6

[42] Gitau, M.N., Mwaniki, F.M., Hofsajer, I.W.: 'Analysis and design of a singlephase tapped-coupled-inductor boost DC- DC converter', J. Power Electron., 2013, 13, (4), pp. 636-646

[43] Dwari, S., Parsa, L.: 'An efficient high-step-up interleaved DC-DC converter with a common active clamp', IEEE Trans. Power Electron., 2011, 26, (1), pp. 66-78

[44] Martinez, W., Imaoka, J., Yamamoto, M.: 'ZCS interleaved boost converter with saturable inductors for reverse-recovery reduction'. 2015 IEEE 11th Int. Conf. Power Electronics and Drive Systems, 2015, pp. 855-861

[45] Tseng, K.-C., Huang, C.-C., Cheng, C.-A.: 'A single-switch converter with high step-up gain and low diode voltage stress suitable for green powersource conversion', IEEE J. Emerg. Sel. Top. Power Electron., 2016, 4, (2), pp. $363-372$

[46] Martinez, W., Imaoka, J., Yamamoto, M., et al.: 'High step-up interleaved converter for renewable energy and automotive applications'. 4th Int. Conf. Renewable Energy Research and Applications, 2015, pp. 1-6 